\title{
Isolation and well-being in the time of lockdown
}

\author{
Lise Bourdeau Lepage ${ }^{1}$ and Balázs Kotosz ${ }^{2}$ \\ ${ }^{1}$ Lyon-3 Jean Moulin University CNSR UMREVS, Lyon, France \\ 2 IESEG School of Management, Paris, France
}

Received: 2 December 2020/Accepted: 17 September 2021

\begin{abstract}
In response to the Covid 19 health crisis, the French government has imposed various measures, referred to as social-distancing measures, including a lockdown with the primary objective of reducing face-to-face interactions between people in order to limit the spread of the virus. This paper seeks to determine whether social-distancing measures and lockdown lead to social isolation for certain groups of people and if they have an impact on French people's well-being. First, it reveals that feelings of social isolation have substantially increased in France during the lockdown and regional differences have occurred. Second, it shows a change in the geography of well-being in France induced by lockdown - with Southerners, originally the happiest, exhibited a strong decline in well-being. Third, estimations show that acclimation to social isolation slows the decline in well-being during lockdown; and that the increase in people's feelings of social isolation during lockdown is a factor which negatively impacts their level of well-being. Fourth, it reveals certain positive influences of residence geographic location on changes in wellbeing levels.
\end{abstract}

JEL classification: I31, I30, I14

Key words: health, France, French regions, social isolation, well-being, Covid-19

\section{Introduction}

In response to the Covid 19 health crisis, the French government has imposed various measures, referred to as social-distancing measures. In spatial terms, these have resulted in the emptying of public spaces, the closure of places where people habitually meet and gather - bars, cafés, restaurants, live-music venues, libraries - and silence, and sometimes sound of birdsong, in urban environments. The most emblematic measure, however, was probably the lockdown of the French population - that is to say, an injunction to stay at home for all but essential reasons - which came into force at noon on Tuesday $14^{\text {th }}$ March 2020 and ended on Monday $11^{\text {th }}$ May 2020. The primary objective of this lockdown was to reduce face-to-face interactions between people in order to limit the spread of the virus.

The effects of lockdown on individuals have been numerous. At the collective level, by restricting the possibilities for meeting other people, it caused a contraction of social life and led people to find new ways of making social interactions possible. 
Individually, lockdown can lead to what is known as social isolation. Indeed, according to De Jong Gierveld et al. (2006, p. 486) "social isolation concerns the objective characteristics of a situation and refers to the absence of relationships with other people. [...] There is a continuum running from social isolation at the one end to social participation at the other. Persons with a very small number of meaningful ties are, by definition, socially isolated." Social isolation has negative effects on people's mental, physical, and cognitive states of well-being (House et al. 1988, Hawkley, Capitanio 2015, Berkman, Syme 1979). Several studies have demonstrated that social isolation can lead to depression, reduce cardiovascular capacity, cause changes in immune responses and sleep patterns, and reduce the life expectancy of affected individuals (Berkman, Syme 1979, Alcaraz et al. 2019). And a recent study conducted in the United States, among a sample of 580,000 adults, showed that social isolation increases the risk of premature death (Alcaraz et al. 2019). We also know that, in general, the proportion of individuals reporting low levels of well-being is higher for those who feel lonely than among other groups (Helliwell 2006). In France, this proportion stands at 45\% compared with 16\% for other groups (Beasley, Perona 2020).

Consequently, through the reduction in face-to-face interactions among the French population, who are by nature social and sensitive beings, by confining them to a reduced living space - within the parameters of their home - and by restricting their freedom of movement and depriving them of contact with nature, social-distancing measures and lockdown can lead to social isolation for certain groups of people and have an impact on French people's well-being.

The aim of our paper is to contribute to the debate on the effects of social isolation on people's well-being by focusing on the French case on a regional scale, in an exceptional context. In the spring of 2020, the "great lockdown" was decided upon, and a large proportion of the country's economic activity was consequently shut down. This situation is unprecedented, and studying its effects is particularly welcome. We are in a position to do this because, during this great lockdown, we conducted a survey on the effects of lockdown on individuals' daily lives among French people and across different regions of France. We developed two hypotheses: first, lockdown has increased feelings of social isolation among the French population, with regional disparities; and second, the increase in people's feelings of social isolation is a factor that had a negative impact on their level of well-being.

Our paper is organized as follows. First, we present our survey methodology. Accordingly, we show that feelings of social isolation have substantially increased in France during the lockdown period and that these have not affected all people in mainland France in the same way. In particular, we will underline a number of regional differences (Section 2). We will then reveal the effects of lockdown on French people's well-being, and regional disparities in this regard. Next, using multiple linear regression, we will estimate the effects of changes in feelings of social isolation on changes in the reported level of well-being of French respondents during lockdown. We tested the following hypothesis: the increase in feelings of social isolation has a negative impact on changes in levels of well-being (Section 3). To conclude, we discuss the generalizability of our results.

\section{Evaluating the effects of social-distancing measures on French people's sense of social isolation}

\subsection{An online survey boosted by the media and an adjusted sample}

During the first week of lockdown in France, on $23^{\text {rd }}$ March 2020, we have announced the launch of a national survey on three social networks: Twitter, LinkedIn, and Facebook. In these different posts, we invited internet users to go to the same independent internet page to complete the questionnaire. The next day, a daily online newspaper, Lyon Capitale, ran a headline on the research conducted by an academic from Lyon University and shared the link to the survey with its readers. From that day on, many journalists brought attention to the subject. We have been interviewed by a variety of media: television (BFM TV, France 3, Arte), radio (including RMC, RCF and Radio Virgin), and national and regional newspapers (20 Minutes, Le Monde, Le Progrès). The survey was also 
disseminated by a number of scientific bodies and organizations, such as the European Regional Science Association, the French National Centre for Scientific Research (CNRS), and French healthcare information-systems company VIDAL. Thus, a large number of French people became aware of the survey and responded to it by going to the web page. As a result, by $10^{\text {th }}$ May, more than 10,976 French people had answered the questionnaire.

The survey was a self-administered questionnaire. This type of survey presents certain advantages. For example, as Sudman, Bradburn (1974) observe, compared with interviews, self-administered surveys reduce respondents' tendency to present themselves in a favorable light.

The aim of this survey was to record the changes that had taken place in French people's day-to-day lives - pace of life, daily habits, social relations, working conditions, employment situations, etc. - and more specifically to evaluate the impact of these factors on their well-being and health. To this end, the questionnaire comprises nine sections. The first introduces the aims of the survey; the second relates to "Life satisfaction and pace of life"; the third deals with "external activities and ICT use"; the fourth with "accommodation"; the fifth focuses on respondents' "situation with regard to work"; the sixth on "assistance during lockdown"; the seventh on "feelings/experiences"; the eighth concerns the personal situation of the interviewee; and the final section thanks respondents for their participation.

Owing to the mode of dissemination of the survey, we had to adjust the sample. To do this, a number of calibration methods exist. These methods enable us to adjust a sample by (re)weighting individuals, using ancillary information available on a number of variables, called calibration variables (Deming, Stephan 1940). The weights produced by these methods are used to calibrate the sample on known population totals in the case of quantitative variables, and on known category frequencies in the case of qualitative variables (Deville, Särndal 1992). The adjustment consists of replacing the initial weights (or "sampling weights") with new weights such that: for a categorical (or "qualitative") calibration variable, the estimated category frequencies for the sample, after adjustment, will be equal to the known population size; and for a numerical (or "quantitative") variable, the estimated total for the variable in the sample, after adjustment, will be equal to the known population total for the variable. This calibration method reduces sampling variance, and in some cases reduces bias due to total non-response.

To adjust the sample, we used an adapted version of the Calmar method. Calmar is an acronym for CALibration on MARgins. This method is "an adjustment technique which adjusts the margins (estimated from a sample) of a contingency table of two or more qualitative variables to the known population margins. However, the program is more general than mere 'calibration on margins,' since it also calibrates on the totals of quantitative variables" (Sautory 1993, p. 2)(Sataury, 1993, 2). We developed the program using IBM's Statistical Package for the Social Sciences (SPSS) software. The linear method was sufficient, as we did not get negative values.

Consequently, we corrected the biases to ensure better representativeness for our sample compared to the adult population of mainland France, who was our target population. Accordingly, we not only eliminated the biases induced by non-response but also reduced comparability concerns. The chosen criteria were age, gender, educational qualifications, and the region of residence adjusted to the population margins of the data from the French National Institution of Statistics and Economic Studies (INSEE). The selected categories were those of the French National Institute of Statistics and Economic Studies (INSEE).

In this way, we obtained a sample of 10,976 individuals, who are representative of the adult population of mainland France in terms of age (Table 1), gender $(52.5 \%$ female, $47.5 \%$ male), educational qualifications (below second degree $56.0 \%$, second degree $16.4 \%$, Diploma Advanced Technician 10.0\%, Bachelor 8.6\%, Master or higher 8.9\%), and region of residence during the spring lockdown from $23^{\text {rd }}$ March to $10^{\text {th }}$ May 2020.

\subsection{The spread of feelings of social isolation through French society during lockdown}

During the great lockdown, feelings of social isolation spread considerably throughout French society (Table 2). While more than $60 \%$ of respondents in France declared that 
Table 1: Distribution of age in our adjusted sample

\begin{tabular}{cc}
\hline Age (years) & Percent \\
\hline $18-30$ & 17.5 \\
$31-39$ & 13.6 \\
$40-49$ & 13.8 \\
$50-59$ & 18.1 \\
$60-69$ & 17.1 \\
$70+$ & 20.0 \\
Total & 100.0 \\
\hline
\end{tabular}

Table 2: Frequency of feelings of isolation among French people

\begin{tabular}{lcc}
\hline & Before lockdown & Since lockdown \\
\hline Never & 60.2 & 32.9 \\
Rarely & 29.6 & 24.2 \\
Often & 7.7 & 27.1 \\
All the time & 1.3 & 14.2 \\
Don't know & 1.2 & 1.6 \\
Total & $100 \%$ & $100 \%$ \\
\hline
\end{tabular}

Notes: The difference between the two periods is significant (Fisher-Freeman-Halton test with p-value $=0.000)$

they never felt socially isolated before lockdown, this figure fell to just under a third during the lockdown period. It should also be noted that $41.3 \%$ of French people reported that they felt socially isolated often or all the time during lockdown, compared to only $9 \%$ before lockdown. However, certain differences can be observed within the French population, particularly with regard to employment situation, age, gender, and region of residence.

\subsection{3 Visible differences within the French population with regard to social isolation during lockdown}

Differences were observed between individuals who work and those who do not work. For example, $63.5 \%$ of those who do not usually work reported never feeling socially isolated before lockdown, compared to $58.6 \%$ of those who do work (Table 3). During lockdown, these figures dropped to $38 \%$ of those who do not work, compared with $32 \%$ of those who do. Another noteworthy fact is that, for those who habitually work, maintaining one's activity during lockdown, i.e., by working from home or continuing to go into the workplace, reduces the frequency of feelings of social isolation. In the case of our study in France, therefore, it was those respondents who usually work but were not able to do so under lockdown who tended to feel socially isolated either often or all of the time. This was the case for almost $47.7 \%$ of this group, whereas only slightly more than a third $(34.7 \%)$ of remote workers and $40.7 \%$ of those who continued to go into their workplace reported similar feelings.

As we can see, being integrated into professional networks is a factor that helps reduce feelings of social isolation during lockdown. The effects of such professional networks are therefore just as favorable in lockdown as in non-lockdown periods (Dykstra 1990, Silverstein, Chen 1996).

Differences in feelings of social isolation were also observed among French respondents according to the type of housing in which they spent lockdown (Table 4). Those who lived in an apartment without a view were the most affected by feelings of social isolation: $56.6 \%$ of this group reported feeling socially isolated often or all the time during lockdown, compared with less than $40 \%$ of people living in a house with a garden. This group of respondents (i.e., in apartments without a view) also experienced the greatest deterioration 
Table 3: Frequency of feelings of isolation among French people according to their employment situation

\begin{tabular}{lccccc}
\hline & $\begin{array}{c}\text { Does not } \\
\text { generally } \\
\text { work }\end{array}$ & $\begin{array}{c}\text { Generally } \\
\text { works }\end{array}$ & $\begin{array}{c}\text { Worked from } \\
\text { home during } \\
\text { lockdown }\end{array}$ & $\begin{array}{c}\text { Went to work- } \\
\text { place during } \\
\text { lockdown }\end{array}$ & $\begin{array}{c}\text { Did not } \\
\text { work during } \\
\text { lockdown }\end{array}$ \\
\hline Never & 63.5 & 58.6 & 58.3 & 59.7 & 58.4 \\
Rarely & 26.9 & 32.7 & 34.3 & 30.7 & 32.2 \\
Often & 8.4 & 7.3 & 6.7 & 9.0 & 7.0 \\
All the time & 1.3 & 1.4 & 0.7 & 0.6 & 2.4 \\
Total & $100 \%$ & $100 \%$ & $100 \%$ & $100 \%$ & $100 \%$ \\
& & \multicolumn{2}{c}{ During lockdown } & & \\
Never & 38.3 & 32.0 & 32.7 & 30.8 & 24.9 \\
Rarely & 19.1 & 32.6 & 32.5 & 28.5 & 27.4 \\
Often & 25.6 & 32.3 & 25.8 & 31.8 & 16.3 \\
All the time & 17.0 & 13.2 & 8.9 & 8.9 & $100 \%$ \\
Total & $100 \%$ & $100 \%$ & $100 \%$ & $100 \%$ & \\
\hline
\end{tabular}

Notes: The difference between workers and non-workers, as between groups of workers in both periods is significant (Fisher-Freeman-Halton tests with p-value $=0.000$ ).

in terms of feelings of social isolation, with the proportion reporting never being affected by such feelings falling from $51.7 \%$ before lockdown to $19 \%$ during.

Table 4: Frequency of feelings of isolation among French people according to their type of accommodation

\begin{tabular}{lcccc}
\hline & $\begin{array}{c}\text { Apartment } \\
\text { without a view }\end{array}$ & $\begin{array}{c}\text { Apartment } \\
\text { with a view }\end{array}$ & $\begin{array}{c}\text { Apartment with a } \\
\text { balcony or terrace }\end{array}$ & $\begin{array}{c}\text { House with a } \\
\text { garden/outdoor space }\end{array}$ \\
\hline \multicolumn{4}{c}{ Before lockdown } \\
Never & 51.7 & 52.3 & 57.7 & 64.8 \\
Rarely & 31.7 & 33.7 & 32.4 & 28.1 \\
Often & 13.0 & 10.1 & 8.6 & 6.5 \\
All the time & 3.7 & 3.9 & 1.3 & 0.6 \\
Total & $100 \%$ & $100 \%$ & $100 \%$ & $100 \%$ \\
& \multicolumn{5}{c}{ During lockdown } \\
Never & 19.0 & 32.5 & 29.6 & 36.8 \\
Rarely & 24.4 & 25.4 & 27.3 & 23.4 \\
Often & 39.7 & 29.1 & 31.6 & 15.3 \\
All the time & 16.9 & 12.9 & 11.5 & $100 \%$ \\
Total & $100 \%$ & $100 \%$ & $100 \%$ & \\
\hline
\end{tabular}

Notes: The difference between accommodation type is significant in both periods (Fisher-FreemanHalton tests with p-value $=0.000$ )

Fewer women than men reported never feeling socially isolated. During lockdown, $29.2 \%$ of women came into this category, compared with $37 \%$ of men (Table 5 ). This is in line with a result observed in France under normal conditions: women generally report feeling isolated more often than men (Beasley, Perona 2020).

Living alone appears to be a factor that fosters social isolation (De Jong Gierveld et al. 2006, Waite, Gallagher 2000, Coleman et al. 2000, Dannenbeck 1995, Wenger et al. 1996). However, only $22.3 \%$ of French people who spent lockdown alone reported never feeling socially isolated during lockdown, compared with $36.5 \%$ of the remainder of the population.

We also observed variations in the frequency of French people's feelings of social isolation between different regions of France (Table 6 ). Almost $50 \%$ of respondents in the 
Table 5: Frequency of feelings of isolation among French people according to their gender

\begin{tabular}{lcccc}
\hline & \multicolumn{2}{c}{ During lockdown } & \multicolumn{2}{c}{ Before lockdown } \\
& Frequency & $\%$ & Frequency & $\%$ \\
\hline Never & 1,962 & Male & & \\
Rarely & 1,290 & 37.0 & 3,357 & 63.3 \\
Often & 1,170 & 24.3 & 1,425 & 26.9 \\
All the time & 826 & 15.6 & 389 & 7.3 \\
Don't know & 58 & 1.1 & 115 & 2.2 \\
Total & 5,305 & 100 & 19 & 0.4 \\
& & 5,305 & 100 \\
Never & 1,653 & 29.2 & & \\
Rarely & 1,368 & 24.1 & 3,250 & 37.3 \\
Often & 1,808 & 31.9 & 1,824 & 8.1 \\
All the time & 728 & 12.8 & 457 & 0.5 \\
Don't know & 113 & 2 & 30 & 1.9 \\
Total & 5,671 & 100 & 110 & 100 \\
\hline
\end{tabular}

Notes: Fisher test p-value $=0.000$; significant difference between male and female.

Hauts-de-France region, in northern France, declared that they never felt socially isolated during lockdown, compared with just $15.2 \%$ of respondents in the western Pays de la Loire region. At the other end of the spectrum, 31.3\% of respondents in Brittany and $32.8 \%$ of respondents in Nouvelle-Aquitaine (in southwestern France) said they felt isolated all the time, compared with $7.5 \%$ of respondents in the Grand Est region (covering most of eastern France) and $8.4 \%$ of respondents based in Île-de-France (the Paris region).

Table 6: Frequency of feelings of isolation among French people according to their region of residence during lockdown (\%)

\begin{tabular}{lcccccc}
\hline & Never & Rarely & Often & All the time & Don't know & Total \\
\hline Auvergne-Rhône-Alpes & 35.0 & 26.6 & 26.8 & 9.9 & 1.7 & 100 \\
Bourgogne-Franche-Comté & 23.2 & 21.1 & 41.1 & 13.6 & 1.0 & 100 \\
(Burgundy-Franche-Comté) & & & & & & \\
Bretagne (Brittany) & 23.0 & 18.0 & 27.4 & 31.3 & 0.4 & 100 \\
Centre-Val de Loire & 37.0 & 18.4 & 33.5 & 9.5 & 1.7 & 100 \\
Grand Est & 38.8 & 25.8 & 24.4 & 7.5 & 3.5 & 100 \\
Hauts-de-France & 49.2 & 16.6 & 20.8 & 9.8 & 3.7 & 100 \\
Île-de-France (Paris region) & 34.8 & 26.3 & 28.6 & 8.4 & 1.9 & 100 \\
Normandie (Normandy) & 36.7 & 19.5 & 30.5 & 12.6 & 0.7 & 100 \\
Nouvelle-Aquitaine & 15.8 & 25.1 & 25.9 & 32.8 & 0.3 & 100 \\
Occitanie & 37.4 & 27.3 & 22.5 & 12.3 & 0.5 & 100 \\
Pays de la Loire & 15.2 & 28.7 & 33.4 & 22.4 & 0.3 & 100 \\
Provence-Alpes-Côte d'Azur & 37.1 & 24.4 & 26.8 & 10.0 & 1.6 & 100 \\
\hline
\end{tabular}

Overall, during lockdown, more French people than usual felt socially isolated at least some of the time (i.e., rarely, often, or all of the time). However, lockdown did not have the same effect on everyone.

\subsection{Differentiated changes in feelings of social isolation throughout France}

Some French people - to be precise, 442 out of the 10,976 individuals in our sample felt less socially isolated than usual. This was the case for $5.4 \%$ of women and $2.8 \%$ of men, who reported feeling less socially isolated during lockdown than before lockdown. Others - 5,256 individuals - felt no difference: for nearly $56 \%$ of men and $42 \%$ of women, lockdown had no effect on their feelings of social isolation. This means that 5,574 of our 
Table 7: Change in feelings of social isolation, by gender and age, among the French population during the spring 2020 lockdown

\begin{tabular}{|c|c|c|c|c|c|c|c|c|}
\hline & \multicolumn{2}{|c|}{$\begin{array}{l}\text { Total numbers } \\
\text { of French } \\
\text { respondents }\end{array}$} & Male & Female & $\begin{array}{c}\text { Age } \\
18-34\end{array}$ & $\begin{array}{c}\text { Age } \\
35-54\end{array}$ & $\begin{array}{c}\text { Age } \\
55-74\end{array}$ & $\begin{array}{l}\text { Age } \\
75+\end{array}$ \\
\hline Less isolated & 442 & $4.1 \%$ & $2.8 \%$ & $5.4 \%$ & $5.9 \%$ & $5.0 \%$ & $2.6 \%$ & $3.5 \%$ \\
\hline No change & 5,256 & $48.8 \%$ & $55.9 \%$ & $42.0 \%$ & $39.2 \%$ & $42.4 \%$ & $53.0 \%$ & $65.7 \%$ \\
\hline More isolated & 5,074 & $47.1 \%$ & $41.3 \%$ & $52.6 \%$ & $54.8 \%$ & $52.5 \%$ & $44.5 \%$ & $30.8 \%$ \\
\hline Total & $10,771^{*}$ & $100 \%$ & $100 \%$ & $100 \%$ & $100 \%$ & $100 \%$ & $100 \%$ & $100 \%$ \\
\hline
\end{tabular}

Notes: ${ }^{*} 205$ individuals out of the 10,976 individuals did not give an opinion.

respondents saw their situation deteriorate, or $47.1 \%$ of the people in our sample; more specifically, $41.3 \%$ of French men and $52.6 \%$ of French women reported an increase in their feelings of social isolation (Table 7).

If we take age group into consideration, we can see that 18- to 34-year-olds were the group most affected. Indeed, almost $55 \%$ of this age group reported an increase in feelings of social isolation, followed closely by 35 - to 54 -year-olds (52.5\%). This result is particularly interesting because, in a normal context, young people are less inclined to report feeling isolated, especially when they are students. Consequently, in a lockdown situation, young people feel isolated more intensely than others, perhaps because at this period in their lives the gregarious instinct is very strong; when physically cut off from their friend groups and/or professional networks, they thus feel isolated.
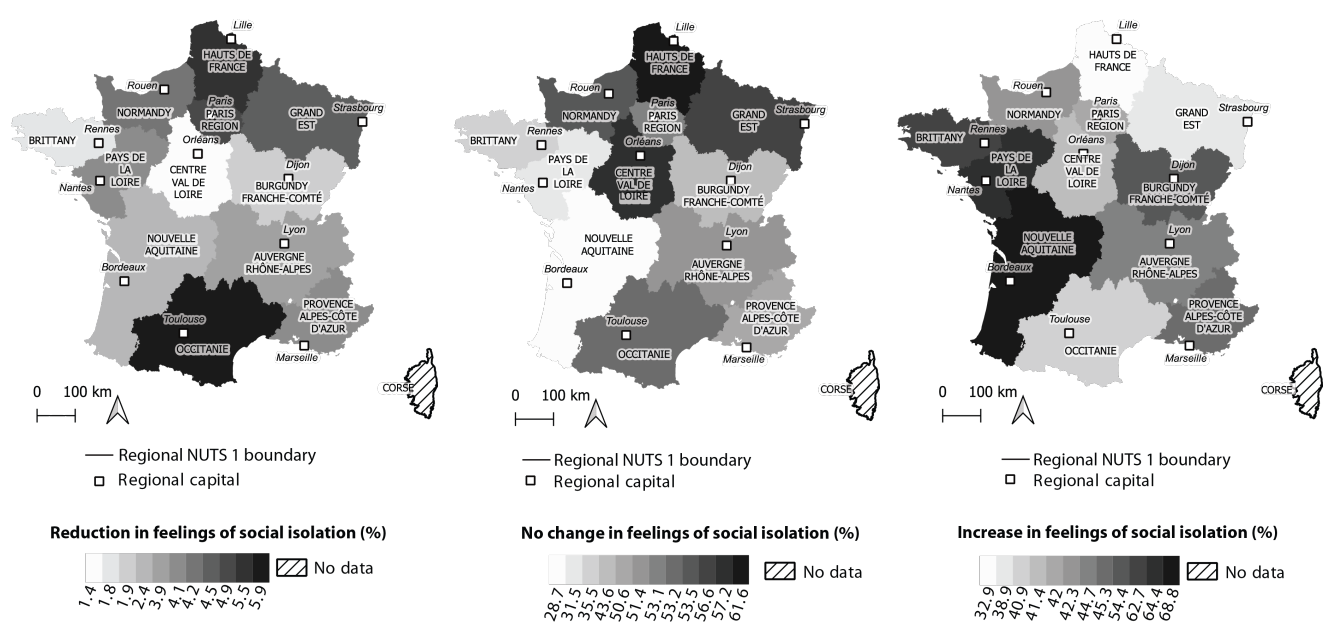

Note: This survey garnered a sample population of 10.976 individuals, who are representative of the adult population of mainland France in terms of age, gender, educational qualifications, and region of residence during the great lockdown from $23^{\text {rd }}$ March to $10^{\text {th }}$ May 2020.

Figure 1: Regional disparities in feelings of social isolation in France during the great lockdown

There are also regional differences in the way feelings of social isolation have changed. In particular, $68 \%$ of respondents from Nouvelle-Aquitaine, $64.4 \%$ of those from Pays de la Loire, and $62.7 \%$ of those from Brittany experienced an increase in feelings of social isolation during lockdown, compared with just $32.9 \%$ of respondents in Hauts-de-France or 38.9 of those of Grand Est (Figure 1).

Thus, residents on the west coast of France were more affected by social isolation during lockdown than other French people. Proportionally, more inhabitants of these regions reported greater social isolation during lockdown than before, compared with other French people. This may be due to the structure of economic activity of these regions. We know that the western coast regions have a significant tourist activity. With the lockdown, this activity has stopped, and workers no longer worked. As a result, 
people lost touch with their clients and colleagues and felt very isolated. In other regions such as Paris Region, teleworking was important during lockdown and people were able to maintain social relations. Thus, the economic structure has probably played a role in the evolution of the feeling of social isolation. But these are just assumptions. Regional cultural differences also matter.

This finding immediately raises a question: how do these changes in feelings of social isolation affect people's well-being? This is the question we shall answer in the next section.

\section{Estimating the effects of feelings of social isolation in terms of French people's well-being}

We can now address the final question that we proposed to answer in this paper: that of the influence of feelings of social isolation on the level of well-being of French people during lockdown. We shall test our hypothesis that individuals who showed an increase in their feelings of social isolation during lockdown experienced a decrease in their level of well-being. But first, we must examine the effect of lockdown on French people's well-being according to their region of residence.

\subsection{Effects of lockdown on French people's well-being. Some regional differences}

In order to gauge respondents' level of well-being and the extent to which this level has changed, we mobilized the World Values Survey method, which, since 1981, has used the Cantril scale to assess well-being (Inglehart et al. 2020). We asked respondents two questions:

1. Using this card, on which 1 means you are "completely dissatisfied" and 10 means you are "completely satisfied", all things considered, how satisfied were you with your life as a whole up until lockdown began?

2. Using this card, on which 1 means you are "completely dissatisfied" and 10 means you are "completely satisfied", all things considered, how satisfied have you been with your life since the beginning of lockdown?

Before analyzing the levels of well-being reported by French people (before and during lockdown), we ensured the reported levels of well-being were comparable between individuals, as we know that not all individuals were necessarily in the same frame of mind when they responded to the survey: certain external factors may have played on their attitude and affected how they responded to the questionnaire. In addition, studies in psychology tell us that some people tend to be more forgiving in their rating than others because their scale of values is not the same, for example. We eliminated the effect induced by variability of state of mind and personality within society. Therefore, a simple adaptation of the item response theory, the Rasch-model (also known as right centering or centering by row) was applied (Füstös et al. 2004)(Füstös et al., 2004). As we did not have information about the general (average) psychological status of each respondent, a larger set of questions positively related to well-being was used. After centering, the variables were rescaled to the original scale by a min-max rescaling process (Bro, Smilde 2003). Thus, we use the term "calibrated level of well-being" to indicate the fact that the level of well-being is comparable between individuals. The change of the calibrated well-being is the difference between the calibrated well-being in the two periods.

The first observation is that during the great lockdown, the well-being of French people was rapidly deteriorating. The calibrated level of well-being decreased from 7.07 (before lockdown) to 5.6 (during lockdown) on a scale of 1 to 10 , a decrease of 1.47 .

The second remark is that lockdown has redistributed the regional cards of well-being within the country. Whereas before lockdown, Southerners were the most satisfied with their lives (their level of well-being varying between 7.25 and 7.34), during the lockdown there are those in the Grand Est (6.08) and Normandy (5.75) regions who were less affected and are now the most satisfied (Figure 2). 

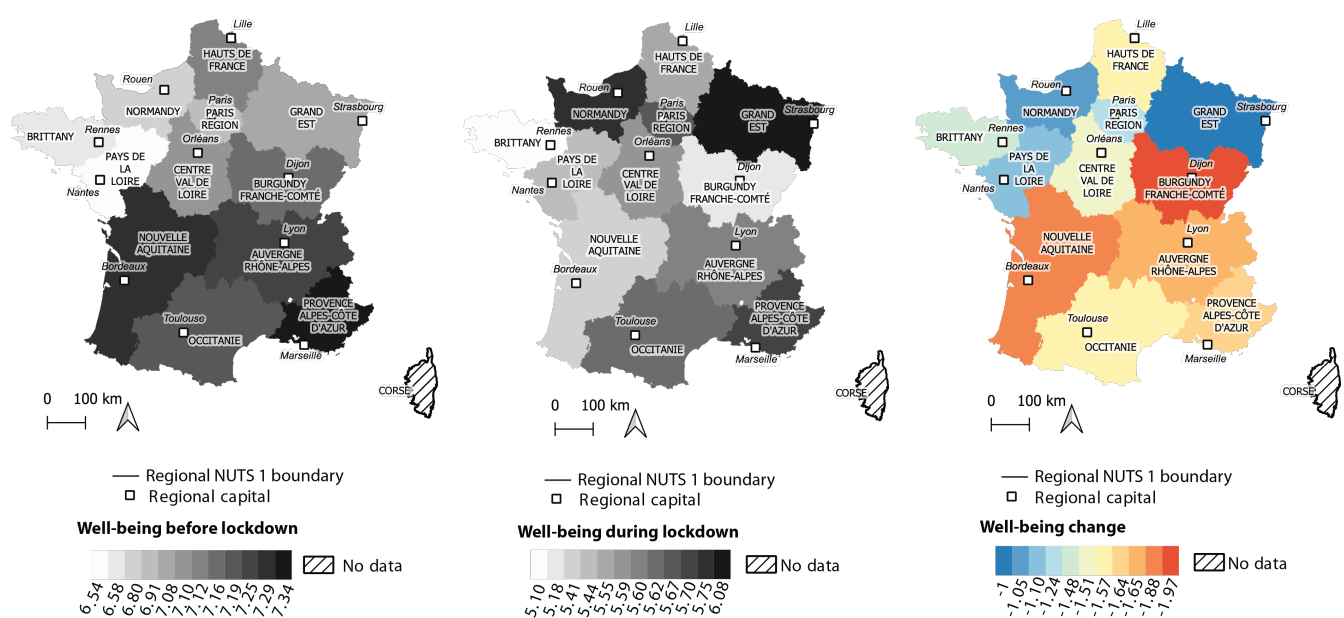

Note: This survey garnered a sample population of 10.976 individuals, who are representative of the adult population of mainland France in terms of age, gender, educational qualifications, and region of residence during the great lockdown from $23^{\text {rd }}$ March to $10^{\text {th }}$ May 2020.

Figure 2: Regional disparities in well-being (calibrated level of well-being)
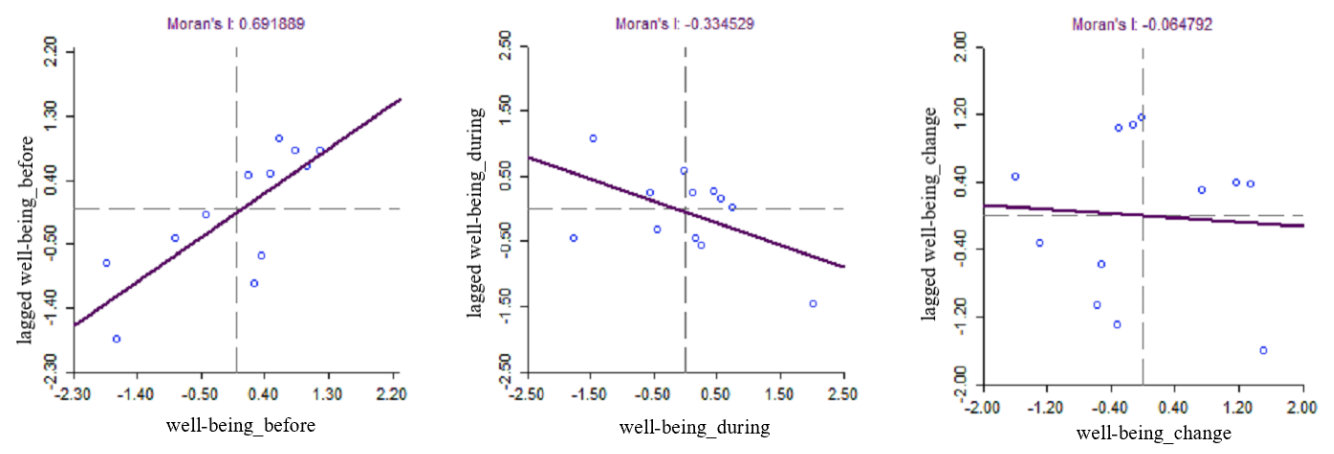

Figure 3: Moran's I coefficient

Before lockdown, the level of well-being exhibited a strong positive spatial autocorrelation, with a Moran's I of 0.691889 significant at 1\% (Figure 3). This means that the well-being differential between advantaged and disadvantaged regions reflected their geographical distance.

This was no longer the case during lockdown. Indeed, the level of well-being exhibited a negative spatial autocorrelation; The pattern of the regions was close to a checkerboard.

But the drop-in well-being levels did not affect all regions in the same way. Residents of Burgundy-Franche-Comté and Nouvelle-Aquitaine displayed the greatest decreases in well-being, while Grand Est and Normandy residents exhibited the smallest decreases. The change in well-being did not present significant spatial autocorrelation: Moran's I was equal to -0.064792 . The change in well-being was therefore random.

\subsection{The relationship between feelings of social isolation and level of well-being}

We can now test the hypothesis that social isolation has a negative impact on the reported level of well-being in any situation. To do this, we must first analyze the link between feelings of social isolation (before and since lockdown) and the reported level of well-being of individuals using linear regression. It transpires that the level of social isolation has a strong influence on the level of well-being.

Thus, our hypothesis is validated in that social isolation clearly has a negative impact on the reported level of well-being in any situation. Accordingly, before and during lockdown, those respondents who were most socially isolated were also those who reported the lowest levels of well-being. Both before and after lockdown, being more isolated 
Table 8: Linear regression of change in well-being

\begin{tabular}{lc}
\hline & Coefficients \\
\hline Constant & $4.643^{* * *}$ \\
Did you feel socially isolated before lockdown? & $(0.077)$ \\
& $0.254^{* * *}$ \\
Have you felt socially isolated since lockdown began? & $(0.019)$ \\
Calibrated level of well-being before lockdown & $-0.517^{* * *}$ \\
& $(0.012)$ \\
& $-0.794^{* * *}$ \\
\hline
\end{tabular}

Notes: Dependent variable: change in calibrated level of well-being. Standard errors in parentheses, *** $=$ p-value $<0.01$. We use the term "calibrated level of well-being" to indicate the fact that the level of well-being is comparable between individuals.

reduces well-being by about 0.5 units. An interesting element is to be noted: more isolation before lockdown may partially compensate for this loss of well-being ( 0.27 units).

The next hypothesis we shall test is acclimation to being socially isolated slows the decline in well-being during lockdown. For this, a linear regression was estimated to establish the general relationship between social isolation and the decrease in well-being (Table 8).

Following our observations of the link between the frequency of feelings of social isolation before lockdown and change in levels of well-being (Table 8), we are inclined to say that a person used to being socially isolated will experience a lesser change in his or her level of well-being during lockdown than others. Indeed, people with a higher level of social isolation before lockdown are those who experienced a smaller reduction in their level of well-being than others (for a person with a one-unit higher isolation before the lockdown, the fall of well-being was 0.254 units less). Our hypothesis is therefore validated.

By contrast, people who experienced a higher level of social isolation during lockdown than others experienced a greater fall in their level of well-being than others. Thus, social isolation prior to lockdown has a small but positive impact on the level of well-being during lockdown, while social isolation during lockdown has a negative impact on the level of well-being.

But how do changes in feelings of social isolation affect changes in levels of well-being? Does it have a positive or negative effect on changes in people's level of well-being? In other words, will a person who feels more socially isolated during lockdown than usual see their level of well-being decrease?

Studies show that, in general, an increase in feelings of social isolation leads to a decrease in individuals' level of well-being, in particular because humans are beings with a gregarious instinct. We therefore hypothesize that the increase in feelings of social isolation is a determinant of the decrease in levels of well-being during lockdown.

\subsection{The impact of changes in feelings of social isolation on changes in levels of well-being}

To test our hypothesis, we conducted multiple linear-regression analysis. Our dependent variable was the change in the calibrated level of well-being, denoted by $Y$. We used a number of explanatory variables from our questionnaire; specifically, we made use of 21 variables, denoted by $X_{j}$ : being more or less isolated during lockdown than before lockdown; boredom; the level of well-being reported before lockdown; having a pet to walk; frequency of physical exercise before and during lockdown; age; gender (reference group: male); region of residence (reference group: Ille-de-France, i.e. the Paris region); employment situation (reference group: does not work in general); activities undertaken at home: music, relaxation, reading, physical exercise; changes in sleep duration (positive if someone sleeps more); information on the health crisis; feeling safe at home; presence of noise nuisance before lockdown; presence of plants at home; presence of pets at home; alcohol consumption; and changes in dietary habits. We encoded the qualitative variables 
using dummy variables, omitting the reference group indicated above. The large quantity of control variables is explained by the intent to avoid biased estimation of the impact of the isolation. However, in the interpretations, we focus only on the most influential ones.

Our model can be expressed in the following way:

$$
Y=\beta_{0}+\beta_{1} X_{1}+\beta_{2} X_{2}+\ldots+\beta_{k} X_{k}+\epsilon
$$

where:

$Y$ represents the change in the calibrated level of well-being;

$X_{j}$ represents the explanatory variables mentioned above;

$\beta$ represents regression coefficients;

$\epsilon$ represents random error.

After the initial regression, we applied a backward elimination with a probability threshold of $10 \%$. Removing the not significant variables has not changed the conclusion, the coefficient of the isolation variables in other model versions was \pm 0.02 different from the reported coefficients in Table 9 .

Table 9: Regression parameters of change in well-being

\begin{tabular}{|c|c|c|}
\hline Variables & $\begin{array}{l}\text { Unstandardized } \\
\text { coefficients }\end{array}$ & $\begin{array}{l}\text { Standardized } \\
\text { coefficients }\end{array}$ \\
\hline Calibrated well-being before lockdown & $\begin{array}{c}-0.787^{* * *} \\
(0.010)\end{array}$ & -0.571 \\
\hline Have you at times been bored since lockdown began? & $\begin{array}{c}-0.506^{* * *} \\
(0.014)\end{array}$ & -0.281 \\
\hline $\begin{array}{l}\text { Do you have a pet with you in lockdown that must be } \\
\text { taken out for walks? }\end{array}$ & $\begin{array}{c}-0.649^{* * *} \\
(0.028)\end{array}$ & -0.153 \\
\hline More isolated during lockdown & $\begin{array}{c}-0.432^{* * *} \\
(0.025)\end{array}$ & -0.132 \\
\hline $\begin{array}{l}\text { Do you have a pet with you in lockdown that does not } \\
\text { need to be taken out for walks? }\end{array}$ & $\begin{array}{c}-0.433^{* * *} \\
(0.023)\end{array}$ & -0.129 \\
\hline $\begin{array}{l}\text { In general, how many times per week have you exercised } \\
\text { since lockdown began? }\end{array}$ & $\begin{array}{c}-0.087^{* * *} \\
(0.006)\end{array}$ & -0.117 \\
\hline Do you have plants in your home during lockdown? & $\begin{array}{c}-0.377^{* * *} \\
(0.027)\end{array}$ & -0.094 \\
\hline Age (in years) & $\begin{array}{c}-0.007^{* * *} \\
(0.001)\end{array}$ & -0.076 \\
\hline $\begin{array}{l}\text { Since lockdown began, have you undertaken the following } \\
\text { activities at home: relaxation/yoga? }\end{array}$ & $\begin{array}{c}0.185^{* * *} \\
(0.027)\end{array}$ & 0.048 \\
\hline Less isolated during lockdown & $\begin{array}{c}0.384^{* * *} \\
(0.054)\end{array}$ & 0.047 \\
\hline Normally works but has not been working during lockdown & $\begin{array}{c}0.170^{* * *} \\
(0.028)\end{array}$ & 0.043 \\
\hline $\begin{array}{l}\text { In general, how many times per week did you exercise } \\
\text { before lockdown? }\end{array}$ & $\begin{array}{c}0.032^{* * *} \\
(0.006)\end{array}$ & 0.039 \\
\hline Region=Hauts-de-France & $\begin{array}{c}-0.199 * * * \\
(0.039)\end{array}$ & -0.034 \\
\hline Region=Auvergne - Rhône-Alpes & $\begin{array}{c}-0.161^{* * *} \\
(0.032)\end{array}$ & -0.034 \\
\hline Region $=$ Grand Est & $\begin{array}{c}0.184^{* * *} \\
(0.039)\end{array}$ & 0.032 \\
\hline Since lockdown, have you felt safe at home? & $\begin{array}{c}0.181^{* * *} \\
(0.040)\end{array}$ & 0.031 \\
\hline $\begin{array}{l}\text { Would you say that, since the start of lockdown, you have } \\
\text { been kept informed about the health crisis and about what } \\
\text { you should be doing? }\end{array}$ & $\begin{array}{c}0.057^{* * *} \\
(0.013)\end{array}$ & 0.030 \\
\hline $\begin{array}{l}\text { Since lockdown began, have you undertaken the following } \\
\text { activities at home: music (playing an instrument)? }\end{array}$ & $\begin{array}{c}0.105^{* * *} \\
(0.025)\end{array}$ & 0.028 \\
\hline
\end{tabular}

Continued on next page 
Table 9: Regression parameters of change in well-being - continued

\begin{tabular}{lcc}
\hline Variables & $\begin{array}{c}\text { Unstandardized } \\
\text { coefficients }\end{array}$ & $\begin{array}{c}\text { Standardized } \\
\text { coefficients }\end{array}$ \\
\hline Are you (male $=0$, female $=1)$ ? & $\begin{array}{c}0.087^{* * *} \\
(0.022)\end{array}$ & 0.027 \\
Since lockdown began, have you undertaken the following & $0.087^{* * *}$ & 0.027 \\
activities at home: physical exercise (working out, weight- & $(0.024)$ & \\
lifting, cycling, etc.)? & $0.100^{* * *}$ & 0.025 \\
Working from home during lockdown & $(0.029)$ & \\
& $0.096^{* * *}$ & 0.024 \\
Since lockdown began, have you consumed more alcoholic & $(0.027)$ & \\
drinks than usual, compared to before lockdown? & $0.024^{* * *}$ & 0.018 \\
Change in sleep duration (hours) & $(0.009)$ & \\
& $0.125^{* * *}$ & 0.017 \\
Region=Normandie (Normandy) & $(0.047)$ & \\
& $-0.060^{* *}$ & -0.017 \\
Before lockdown, did you experience noise nuisance (street & $(0.023)$ & \\
noise, noise from neighbors, etc.) when at home? & $-0.050^{* *}$ & -0.015 \\
Since lockdown began, have you changed your dietary & $(0.023)$ & \\
habits, compared with before lockdown? & $5.293^{* * *}$ & \\
Constant & $(0.105)$ & \\
&
\end{tabular}

Notes: Dependent variable: change in calibrated level of well-being. Standardized coefficients are calculated as the unstandardized coefficient divided by the standard deviation of the independent variable and multiplied by the standard deviation of the dependent variable. These unitless coefficients show the comparable effect size. The model was tested for multicollinearity issues, the highest VIF $=1.529$ for the age variable, thereby no disturbing multicollinearity was detected. Heteroskedasticity corrected standard errors in parentheses, ${ }^{*}=$ p-value $<0.1,{ }^{* *}=$ p-value $<0.05, * * *=$ p-value $<0.01$.

The results show that our hypothesis is validated (Table 9). Specifically, people who felt more isolated during lockdown than before experienced a decrease in their level of well-being of 0.432 units compared to those who did not experience a change in their level of social isolation. Conversely, people who felt less isolated during lockdown than before experienced an increase in their level of well-being of 0.384 units compared to those who did not experience a change in their level of social isolation.

So, changes in feelings of social isolation do indeed have an influence on changes in levels of well-being (Table 9). It is the third most important factor in determining changes in levels of well-being, after the level of well-being before lockdown, boredom since lockdown, and before having a pet to be taken out. The result concerning "ownership of pets that need to be walked" is interesting. Ordinarily, the company of a pet is recommended to improve people's levels of well-being, especially for the elderly (Cherniack, Cherniack 2014, McNicholas 2014). It helps them feel less alone and forces them to go outside regularly and take exercise. In this way, they create links with the outside world, sometimes talking to other pet owners, all of which may help them feel better. Pet therapy also reinforces this point. During lockdown, however, these pets did not produce the same effects as usual, perhaps because social-distancing measures prevented people from engaging in the activities they usually would with their pets: walking in the forest, meeting neighbors in their local area during outings with their pet, etc. Such explanations are mere speculation on our part, though, as a qualitative survey of pet owners would be required to provide definitive answers.

Other results deserve our attention. Indeed, we observed that, in certain cases, the region of residence can have a positive or negative impact on changes in levels of wellbeing. For example, people who live in the Hauts-de-France, Auvergne-Rhône-Alpes, and Bourgogne-Franche-Comté regions experienced, respectively, decreases in their level of well-being of $0.133,0.161$ and 0.231 units compared to those who live in the Ile-deFrance (Paris) region. Conversely, people who live in the Grand Est and Normandy regions experienced increases in their level of well-being of 0.184 units and 0.125 units, respectively, compared to those who live in the Paris region. 


\section{Conclusion}

We have shown that social-distancing measures have had a significant effect on the degree to which French people feel socially isolated. This feeling of social isolation has spread throughout France, especially in western regions. Residents of Nouvelle-Aquitaine, Pays de la Loire, and Brittany have been particularly affecting during lockdown compared to those of the Hauts-de-France and Grand Est regions. Our study therefore reveals that certain categories of French people are more vulnerable than others to social-distancing measures.

We highlighted a change in the geography of well-being in France induced by lockdown. While residents of southern regions had the highest levels of well-being before lockdown, this is no longer the case during lockdown. Residents of the Normandy and Grand Est regions exhibited the highest well-being levels.

Our study shows that, in a context of lockdown, the link between feelings of social isolation and reported well-being among French people continues to exist. Indeed, our study also demonstrated that the increase in people's feelings of social isolation during lockdown was a factor that had a negative impact on their level of well-being during lockdown. We were also able to reveal certain positive influences of residence location on changes in well-being levels.

Some of our results are hard to generalize because the cultural context plays a major role in people's evaluation of feelings of social isolation De Jong Gierveld et al. (2006). For example, sociocultural factors must be taken into account. Discussions on the theme of the UCLA (University of California Los Angeles) loneliness scale or De Jong Gierveld scale remind us of this (Russell et al. 1980, Russell 1996, De Jong Gierveld et al. 2006).

However, our results regarding the drop in well-being levels due to lockdown have been observed in other studies. This is the case for the study conducted by van Leeuwen, Bourdeau-Lepage (2020), for instance, which shows that, with lockdown, the average level of well-being (on a scale of 1 to 10) of Dutch people decreased from 8 to 6.7 (a drop of 1.3 points). This study also revealed territorial differences in well-being levels, especially between urban and rural areas.

But what has been the impact of social-distancing measures and lockdown on the physical, emotional and cognitive health of French people? A paper by Brooks et al. (2020) reveals that the psychological impact of lockdown is negative on individuals, and more specifically that lockdown generates anger, confusion and post-traumatic stress. Our questionnaire included questions on individuals' emotional, cognitive and physical state. It would be interesting to try to see whether there is a link between French people's feelings of isolation, levels of well-being, and states of health, in order to make progress in understanding the effects of lockdown on individuals.

\section{Acknowledgement}

The authors thank the IDEX of LYON for its financial support of the INTERLUDE research project. 


\section{References}

Alcaraz K, Eddens K, Blasé J, Diver R, Patel A, Teras L, Stevens V, Jacobs E, Gapstur S (2019) Social isolation and mortality in US black and white men and women. American Journal of Epidemiology 188: 102-109

Beasley E, Perona M (2020) Dimensions de la solitude en France. Observation du bienêtre du cepremap 2020 1: 9 pages

Berkman LF, Syme SL (1979) Social networks, host resistance, and mortality: A nine-year follow-up study of Alameda County residents. American Journal of Epidemiology 109: 186-204. CrossRef.

Bro R, Smilde AK (2003) Centering and scaling in component analysis. Journal of Chemometrics 17: 16-33. CrossRef.

Brooks S, Webster R, Smith L, Woodland L, Wessely S, Greenberg N, Rubin GJ (2020) The psychological impact of quarantine and how to reduce it: Rapid review of the evidence. Lancet 395: 912-920. CrossRef.

Cherniack EP, Cherniack AR (2014) The benefit of pets and animal-assisted therapy to the health of older individuals. Current Gerontology and Gerontological Research 1-9. CrossRef.

Coleman M, Ganon L, Fine M (2000) Reinvestigating remarriage: Another decade of progress. Journal of Marriage and the Family 62: 1288-1307. CrossRef.

Dannenbeck C (1995) Im Alter einsam? Zur Strukturveränderung sozialer Beziehungen im Alter. In: Bertram H (ed), Das Individuum und seine Familie. Leske Budrich, Opladen, Germany, 125-156

De Jong Gierveld J, van Tilburg TG, Dykstra PA (2006) Loneliness and social isolation. In: Perlman D, Vangelisti A (eds), The Cambridge Handbook of Personal Relationships. Cambridge University Press, Cambridge, UK, 485-500. CrossRef.

Deming WE, Stephan FF (1940) On a least squares adjustment of a sampled frequency table when the exact totals are known. Annals of Mathematical Statistics 11: 427-444. CrossRef.

Deville JC, Särndal CE (1992) Calibration estimators in survey sampling. Journal of the American Statistical Association 87: 376-382. CrossRef.

Dykstra PA (1990) Next of non-kin. The importance of primary relationships for older adults' well-being. Swets \& Zeitlinger, Amsterdam/Lisse, Netherlands. CrossRef.

Füstös L, Kovács E, Meszéna G, Simonné Mosolygó N (2004) Alakfelismerés. Sokváltozós statisztikai módszerek. Budapest, Új mandátum kiadó

Hawkley L, Capitanio J (2015) Perceived social isolation, evolutionary fitness and health outcomes: A lifespan approach. Philosophical Transactions of the Royal Society B 370. CrossRef.

Helliwell J (2006) Well-being, social capital and public policy: What's new? The Economic Journal 116: C34-C45. CrossRef.

House JS, Landis KR, Umberson D (1988) Social relationships and health. Science 241: 540-545. CrossRef.

Inglehart R, Haerpfer C, Moreno A, Welzel C, Kizilova K, Diez-Medrano J, Lagos M, Norris P, Ponarin E, Puranen B (2020) World values survey: All rounds - countrypooled datafile. Madrid, Spain \& Vienna, Austria: JD Systems Institute \& WVSA Secretariat [version: http://www.worldvaluessurvey.org/WVSDocumentationWVL.jsp] 
McNicholas J (2014) The role of pets in the lives of older people: A review. Working with Older People 18: 128-133. CrossRef.

Russell D, Peplau LA, Cutrona CE (1980) The revised UCLA loneliness scale: Concurrent and discriminant validity evidence. Journal of Personality and Social Psychology 39: 472-480. CrossRef.

Russell DW (1996) UCLA loneliness scale (Version 3): Reliability, validity, and factor structure. Journal of Personality Assessment 66: 20-40. CrossRef.

Sautory O (1993) La macro Calmar. redressement d'un échantillon par calage sur marges. Document de travail F9310 de la DSDS, Insee

Silverstein M, Chen X (1996) Too much of a good thing? intergenerational social support and the psychological well-being of older persons. Journal of Marriage and Family 58: 970-982. CrossRef.

Sudman S, Bradburn NM (1974) Response effects in surveys: A review and synthesis. Aldine, Chicago. CrossRef.

van Leeuwen E, Bourdeau-Lepage L (2020) Spatial differences and the impact of the lockdown on well-being in the Netherlands. SSRN Electronic Journal 3 June. CrossRef.

Waite L, Gallagher M (2000) The case for marriage: married people are happier, healthier and better off financially. Doubleday, New York. CrossRef.

Wenger CG, Davies R, Shahtahmasebi S, Scott A (1996) Social isolation and loneliness in old age: Review and model refinement. Ageing and Society 16: 373-358. CrossRef.

c) (7) (8) (C) 2021 by the authors. Licensee: REGION - The Journal of ERSA, European Regional Science Association, Louvain-la-Neuve, Belgium. This article is distributed under the terms and conditions of the Creative Commons Attribution, Non-Commercial (CC BY NC) license (http://creativecommons.org/licenses/by-nc/4.0/). 